\title{
Wasted Lives. Borders and the Right to Life of People Crossing Them
}

\author{
Thomas Spijkerboer ${ }^{1}$ \\ Professor of Migration Law, Vrije Universiteit Amsterdam, Amsterdam, \\ The Netherlands
}

\begin{abstract}
States are obliged to protect the right to life by law. This article analyses the way in which states do this in the field of aviation law, maritime law and the law on migrant smuggling. A comparative description of these fields shows that states differentiate in protecting the right to life. Regular travellers benefit from extensive positive obligations to safeguard their right to life, whereas the lives of irregularised travellers are protected first and foremost by combating irregularised migration and, if the worst comes to pass, by search and rescue. The right of states to exclude aliens from their territories leads to exclusion of irregularised travellers from their main positive obligations under the right to life. This situation is analysed through Zygmunt Bauman's notion of 'wasted lives'. The contrast with aviation and maritime law makes clear that this situation is the outcome of human choice, which can be changed.
\end{abstract}

\section{Keywords}

border deaths - migration - right to life - aviation law - maritime law - migrant smuggling

1 This article has been made possible by the dedicated research assistance of Anne de Hingh, Banafsheh Mogadassi Mahalatti and Judith Verbeek. It was inspired by critical feedback to the Human Costs of Border Control project by Marc Schuilenburg on 29 October 2013. Pieter Boeles has been crucial in overcoming blockades during the writing process. The draft has further benefited from the perceptive comments of an anonymous reviewer, and of Paolo Cuttitta, Marieke de Hoon, Lisa Komp, Pablo Mendes De Leon, as well as from the feedback during the Seventh Bergen aan Zee seminar on 2-3 June 2015, and during a seminar at the Law Faculty in Lund on 13 November 2015. Research for this article was conducted as part of

(C) THOMAS SPIJKERBOER, 2017 | DOI 10.1163/15718107-08601004

This is an open access article distributed under the terms of the Creative Commons Attribution 4.0

Unported (CC-BY-NC 4.0) License. http://creativecommons.org/licenses/by-nc/4.0/ 
In the past few years, there has been increasing attention for the people dying during their travel to Europe, the USA and Australia. ${ }^{2}$ Deaths typically occur when people seek to cross borders while trying to evade border controls. ${ }^{3}$ The policy response to the phenomenon has been twofold. First, states seek to prevent deaths by combating irregularised migration as such. Second, states have increased the capacity for maritime search and rescue. These responses can be part of the same operation, as in Italy's Operation Mare Nostrum and the European Union's Operation Triton.

Irregularised migrants are not the only people who travel across borders. People boarding an airplane or a ferry also run risks. Over the past century, states have created and implemented legal mechanisms which seek to enhance the safety of cross-border sea and air travellers, most notably through regulations based on the Convention on International Civil Aviation (commonly referred to as the Chicago Convention, hereafter CC), ${ }^{4}$ the Convention for the Safety of Life at Sea (hereafter SOLAS), ${ }^{5}$ the Convention on Maritime Search and Rescue (hereafter SAR), ${ }^{6}$ as well as the Protocol against the Smuggling of Migrants by Land, Sea and Air (hereafter Smuggling Protocol). ${ }^{7}$

2 See e.g. Tamara Last: State-of-the-art on border deaths in the Mediterranean: do we know what's happening at our borders, manuscript on file with author; T. Brian and F. Laczko, Fatal Journeys. Tracking Lives Lost During Migration (International Organization for Migration, Geneva 2014); D.E. Martínez, R.C. Reineke, R. Rubio-Goldsmith, and B.O. Parks, 'Structural Violence and Migrant Deaths in Southern Arizona: Data from the Pima County Office of the Medical Examiner, 1990-2013', 2 Journal on Migration and Human Security (2014) pp. 257-286; L. Weber and S. Pickering, Globalization and Borders. Death at the Global Frontier (Palgrave Macmillan, Basingstoke, 2011); E. Kiza, Tödliche Grenzen. Die fatale Auswirkungen europäischer Zuwanderungspolitik (Lit Verlag, Zürich, 2008).

3 The main data sets, based on different sources, are Deaths at the Borders: Database for the Southern EU, 12 May 2015, Tamara Last, <www.borderdeaths.org/?page_id=11 >, visited on 23 December 2015; United Against racism: List of Deaths, <http://www.unitedagainstracism .org/wp-content/uploads/2015/o6/Listofdeaths22394June15.pdf>, visited on 23 December 2015; the Fortress Europe Blog, <fortresseurope.blogspot.nl/p/la-strage.html>, visited on 23 December 2015; and the Missing Migrants project of the International Organization for Migration, <missingmigrants.iom.int/en/latest-global-figures $>$, visited on 23 December 2015. These data show that the vast majority of migrants dies at sea, which is the reason why in this paper the legal regulation of the safety of overland travel will not be addressed separately.

415 UNTS 295.

$5 \quad 1184$ UNTS 277 .

$\begin{array}{ll}6 & 1405 \text { UNTS } 97 .\end{array}$

$7 \quad 2241$ UNTS 480. 
Article 6 of the International Convention on Civil and Political Rights (ICCPR) provides that every human being has the inherent right to life, which shall be protected by law. Article 2 of the European Convention on Human Rights (ECHR) provides that everyone's right to life shall be protected by law. ${ }^{8}$ As these provisions make clear, international law requires states to make law safeguarding life. In this article, the international law on traveller safety will be analysed as law protecting the right to life against the specific risks related to cross-border travel. To this end, the different legal regulations will be compared on four points: the institutional context, the procedures for making new law, the content of the law, and (extraterritorial) jurisdiction.

In maritime and aviation law, the terms crew and passenger are used. This makes sense in these contexts because crew have specific responsibilities which passengers do not have. In this article, that differentiation is not useful as it is not concerned with the responsibilities of crew but with those of states. In the context of migrant smuggling, the terms (illegal/irregular) migrant and refugee are used, and the characterisation of a person as a refugee has specific legal consequences. Among irregularised travellers, the difference between passengers and crew may be hard to make because the crew may consist of migrants who get a discount if they sail the boat ${ }^{9}$ - people may be crew and passenger. The terms crew, passenger, (irregular/illegal) migrant and refugee have connotations which are specific to the different contexts that will be reviewed in this article. However, the aim of the present analysis is to develop an overarching comparative analysis of the law protecting the right to life of people crossing borders, encompassing migrants, irregularised migrants, ${ }^{10}$ tourists, refugees, business people, crew or passengers. Therefore, the use of contextspecific terms would be counter-productive. A generic term that can be

8 See extensively P. van Dijk, G.J.H. Hoof, F. van Hoof, A. van Rijn and L. Zwaak (eds.) Theory and Practice of the European Convention on Human Rights (fourth edition, Intersentia, Antwerp 2006), p. 355 et seq; D.J. Harris, M. O’Boyle, E.P. Bates, C.M. Buckley, 'Law of the European Convention on Human Rights ( $2^{\text {nd }}$ ed., Oxford University Press, Oxford 2009), pp. 42-46; ECtHR 28 October 1998, Osman v. United Kingdom, Appl. No. 23452/94; ECtHR 3 April 2001, Keenan v. United Kingdom, Appl. No. 27229/95; ECtHR (GC) 30 November 2004, Öneryildiz v. Turkey, Appl. No. 48939/99.

9 For example H. Lucht, Darkness before Daybreak. Africans Migrants Living on the Margins in Southern Italy Today (University of California Press, Oakland, CA, 2012) pp. 129-130.

10 I use the term 'irregularised' in order to acknowledge that it is institutional and political processes that render people illegal, comp. H. Bauder: 'Why We Should Use the Term 'Illegalized' Refugee or Immigrant: A Commentary', International Journal of Refugee Law 2014, pp. $327-332$. 
used in all contexts is preferable, and the term traveller will be used for that reason. ${ }^{11}$

The right to life of cross-border travellers is regulated within three contexts: the context of air travel (through the International Civil Aviation Organization, ICAO, mainly on the basis of the Chicago Convention); the context of regular sea travel (through the International Maritime Organization, IMO, mainly on the basis of SOLAS); and the context of irregularised sea travel (in a purely intergovernmental context which is facilitated by the United Nations Office on Drugs and Crime, UNODC, mainly via the Smuggling Protocol). Search and rescue concerns both regular and irregularised travel, which leads to complications as we will see.

\begin{tabular}{|c|c|c|}
\hline International & International Maritime & United Nations Office \\
\hline Civil Aviation & Organization & on Drugs and Crime \\
\hline
\end{tabular}

\begin{tabular}{llll}
\hline Convention & $\begin{array}{l}\text { Convention Safety } \\
\text { of Life at Sea }\end{array}$ & Search and & Smuggling Protocol \\
International & & Rescue & \\
Civil Aviation & & Convention & \\
\hline
\end{tabular}

The comparison will show that the law safeguarding the right to life of irregularised travellers is underdeveloped compared to that safeguarding the right to life of regular travellers. Promoting safety is among the primary aims of the ICAO and the IMO, but is merely a secondary aim of the Smuggling Protocol. The ICAO and IMO have, to different degrees, adopted transnational law making procedures resulting in data-driven, performance-based norms which apply globally, bypassing jurisdictional issues. In contrast, the safety of irregularised travellers is subject to traditional intergovernmental treaty making procedures aimed at prohibiting cross-border movement of people, where territoriality is a major concern. States have assumed far-reaching positive obligations to protect the right to life of regular travellers, but recognise only very limited obligations vis-à-vis irregularised travellers. However, the legal concepts used to limit positive obligations concerning irregularised travellers become questionable when one notices that comparable issues are found entirely unproblematic

11 The term traveller is also used in S. Mau et al., 'The Global Mobility Divide: How Visa Policies Have Evolved over Time', Journal of Ethnic and Migration Studies (2015), pp. 1-22; as well as in M. Stierl: 'A sea of struggle - activist border interventions in the Mediterranean Sea', 20:5 Citizenship Studies (2016), pp. 561-578. 
in the context of regular travellers. States exclude irregularised travellers from their territories; in the same gesture they exclude them from positive obligations under the right to life. This can best be understood by using the concept of 'wasted lives', coined by Zygmunt Bauman, as is argued in a final section.

\section{The UN Institutions Involved in Traveller Safety}

The right to life of air travellers and regular sea travellers is addressed through two specialised agencies of the UN which have been explicitly tasked with the aim of promoting safety. The right to life of irregularised sea travellers, however, is addressed through an office in the general secretariat of the UN. Promoting safety is not one of its aims, and it is only a secondary aim of the Smuggling Protocol.

\subsection{ICAO \& IMO}

The regulation of the safety of air travellers and of regular sea travellers takes place in the context of two well established institutions: the International Civil Aviation Organization, based in Montreal, and the International Maritime Organization, based in London. They were established by international treaty, ${ }^{12}$ and explicitly designated as a specialised UN agency. ${ }^{13}$ The highest organs of both organisations are their Assemblies. ${ }^{14}$ They both have a Council, which is a permanent body consisting of a smaller number of states. ${ }^{15}$ States are elected as members of the Council based on considerations of their economic importance for the sector, and geographical balance. ${ }^{16}$ The Assembly and the Council are competent to make law, which will be dealt with in greater detail below. The Convention establishing the IMO establishes the Maritime Safety Committee. ${ }^{17}$ It consists of all the member states, and is competent to consider

\footnotetext{
12 Article $43 \mathrm{CC}$ and the Convention on the Intergovernmental Maritime Consultative Organization (IMCO, renamed IMO in 1982), 289 UNTS 4.

13 ICAO Resolution A1-2 of 13 May 1947; Convention on the Privileges and Immunities of the Specialized Agencies, 33 UnTS 521; Article 45 IMco Convention; Article I Agreement on the Relationship Between the United Nations and the Intergovernmental Maritime Consultative Organization, 289 UNTS 25 .

14 Article 48-49 CC; Articles 13-16 Imo Convention.

15 Article 50-55 CC; Article 17-27 IMo Convention.

16 Article 5o(b) cc; Article 17 Imco Convention.

17 Articles 27-31 Imo Convention.
} 
any matter directly affecting maritime safety. These organs all have majority voting. ${ }^{18}$ The ICAO and the IMO have a Secretary-General ${ }^{19}$ and a secretariat. ${ }^{20}$

The aims of the organisations are specified in the international treaties by which they are created. The Chicago Convention specifies nine aims, three of which relate to safety, three to fair competition without discrimination based on nationality, and three to further development of civil aviation. ${ }^{21}$ The IMO has five specific aims, which are less clearly stated than the ICAO aims. The first two aims which are mentioned together are promoting the highest practicable standards on safety and efficiency of navigation; the aim that gets most text is the prevention of discriminatory and unfair practices. ${ }^{22}$

\subsection{The Institutional Framework for Irregularised Travellers}

The first initiatives to address the "grave danger to life arising from unsafe practices associated with alien smuggling by ships" were taken in 1993 simultaneously in the framework of the IMO and the UN Commission on Crime Prevention and Criminal Justice. ${ }^{23}$ Both resolutions propose suppression of smuggling by means of criminal law. The IMO resolution stated as its aim to "co-operate and take, as a matter of the highest priority, all necessary action to prevent and suppress the unsafe practices associated with alien smuggling by ships". ${ }^{24}$ The UN General Assembly resolution put more emphasis on the criminal law aspect: "international criminal groups often convince individuals to migrate illegally (...) thus bringing great harm to the States concerned", and "such activities endanger the lives of those individuals". States are urged "to frustrate the objectives and activities of smugglers of aliens and thus to protect would-be migrants from exploitation and loss of life, inter alia, by amending criminal laws, if necessary, to encompass the smuggling of aliens and by establishing or improving procedures to permit the ready discovery of false travel documents supplied by smugglers". The resolution reaffirms "the need to observe fully international and national law in dealing with the smuggling

18 Article 48 and 52 CC; Articles 43 and 62 Imo Convention.

19 Article $54 \mathrm{CC}$; Article 22 Imo Convention.

20 Articles 58-6o cC; Articles 47-52 Imo Convention.

21 Article $44 \mathrm{Cc}$.

22 Article 1 Imo Convention.

23 See A. Gallagher and F. David, The International Law of Migrant Smuggling (Cambridge University Press 2014) pp. 29-34.

24 Imo Resolution A.773(18), 4 November 1993. Comp. Imo Circular msc/Circ.896 of 16 December 1998, urging states to ensure compliance with solAs standards and to "prevent and suppress unsafe practices associated with trafficking or transport of migrants by sea", Msc/Circ.896 Annex p. 2. 
of aliens, including the provision of humane treatment and strict observance of all the human rights of migrants", and specifically refers to international refugee law. ${ }^{25}$ Having been called upon to do so, the Commission on Crime Prevention and Criminal Justice issued reports on smuggling. ${ }^{26}$

Initiatives to draft an international convention on migrant smuggling were circulated in the Council of Europe and the Imo. ${ }^{27}$ Eventually, these initiatives were channelled via the UN Commission on Crime Prevention and Criminal Justice. This brought the issue under the umbrella of the un Office on Drugs and Crime (UNODC) in Vienna. This office came about in 1997 as a merger of the United Nations Drug Control Programme and the Centre for International Crime Prevention. The organisation is part of the general secretariat of the United Nations, and seems not to be based on a convention or another formal international law basis. ${ }^{28}$ Its aims are defined as "[d]rug control, crime prevention and combating international terrorism in all its forms and manifestations", which includes "money-laundering and trafficking in women and children". 29 Victims of drugs or international crime are not mentioned, let alone that their safety is an explicit aim. Three sets of Conventions are within the working area of UNODC: conventions on crime in general (including the Convention against Transnational Organized Crime ${ }^{30}$ and the related Protocols); conventions on drugs; and on terrorism. Unlike the ICAO or the IMO, the UNODC has no formal mechanism for adopting conventions, standards, and recommendations.

By resolution 53/111, of 9 December 1998 (adopted without a vote), the General Assembly established an intergovernmental Ad Hoc Committee for the purpose of elaborating the international convention against transnational organised crime and three additional international legal protocols. ${ }^{31}$ The Convention against Transnational Organized Crime institutes a Conference of the Parties, which does not have the power to adopt rules binding state parties

\footnotetext{
25 UNGA Res. 48/102, 20 December 1993.

26 Gallagher and David, supra note 23, p. 31.

27 Ibid., pp. 32-34.

28 I spent an hour or so calling the UNODC secretariat in Vienna asking for the legal basis of the organization. This was not an issue anyone I had on the phone had ever thought of before, or thought of as relevant. I kept being referred to other people. When the fourth person I spoke to at some length (who was quite well informed about the institutional context of UNODC, but no about the formal aspects of it) referred me back to the person I had begun calling, I ended making calls.

29 UN Doc A/51/950, 14 July 1997, p. 48.

$30 \quad 2225$ UNTS 209.

31 For reports of the 13 drafting sessions, see online at <http://www.unodc.org/unodc/en/ treaties/CTOC/background/adhoc-committee.html>.
} 
(Article 32). The Conference will be supported by a secretariat which also has no formal powers (Article 33). The Convention is to be supplemented by protocols, which need separate acceptance by each state in order to become binding (Article 37). In 1999, the Ad Hoc Committee set up to draft a transnational organised crime convention was tasked with addressing, in that context, trafficking and transportation of migrants, including by sea. ${ }^{32}$ One of the protocols adopted in this context is the Smuggling Protocol. The Smuggling Protocol in its preamble indicates that the states parties are primarily concerned with the "great harm to the States concerned" following from migrant smuggling, and in the next consideration indicates that the signatory states are "also concerned that the smuggling of migrants can endanger the lives or security of the migrants involved". This indicates that safety is a secondary aim of the Protocol, in addition to combating crime as the primary aim.

\section{$2.3 \quad$ Summary}

At the institutional level, we can observe a clear distinction. The international law protecting the right to life of regular travellers is established in the context of formal UN agencies, governed by member state representative bodies with clear competencies. Traveller safety is one of the explicit aims of these organisations. Instead, international law relating to irregularised travellers is established under the umbrella of an informal office within the general secretariat of the UN, which is aimed at combating crime and has not been tasked specifically with protecting the right to life. The Smuggling Protocol mentions the safety of migrants only as a secondary aim. Search and rescue, which aims at protecting the right to life of both regular and irregularised sea travellers without making an explicit distinction between them, falls under the remit of the IMO. This clearly differentiated institutional context comes with a differentiation in the importance given to the right to life of, on the one hand, regular travellers and, on the other hand, irregularised sea travellers.

\section{Law-making Competence}

The three UN organisations involved have different rules on the way in which law - including law protecting the right to life - can be made. All three sets of rules are based on the traditional assumption that states are Herre der Verträge, and can only be bound to international law if they have consented to be so. However, despite this common point of departure, the law-making systems

32 UNGA Res. 53/111, 20 January 1999. 
in the three organisations are radically different. In the UNODC context, lawmaking requires making traditional intergovernmental treaties, whereas the ICAO has a permanent transnational uniform regulation process (although it lacks central enforcement powers). The IMO is hybrid, with intergovernmental elements if a topic is framed as being about irregularised travellers, and more transnational elements if regular travellers are the focus of regulation.

\subsection{Intergovernmentalism on Irregularised Travellers}

The Convention against Transnational Organized Crime can be amended by a two third majority of the Conference of the Parties, ${ }^{33}$ but the amended version only becomes binding after "ratification, acceptance or approval by State Parties". ${ }^{34}$ This means that a traditional intergovernmental method of lawmaking is being used in this context. States can only be bound by rules which they have explicitly accepted. The UNODC has no formal or factual regulatory competence. The UNODC did publish a Model Law against the Smuggling of Migrants in 2010, in response to a request by the UN General Assembly to the un General Secretary. The Commentary to the model law specifies which articles of the Smuggling Protocol are mandatory, but consistently mentions that while compliance is mandatory, the manner in which compliance may be achieved may vary. The Model Law is not presented as something states have to follow. Only the provision on jurisdiction is considered mandatory also in the manner in which it is implemented; hence on this point the Model Law is presented as something from which no substantive deviation is possible because its content directly follows from the Protocol itself. ${ }^{35}$ In The UNODC context, this traditional intergovernmental law-making system is all there is.

\subsection{Majority Law-making in ICAO and IMO}

The treaties establishing the ICAO and the IMO were concluded through the same traditional intergovernmental law making process which was used to conclude the Smuggling Protocol. However, these traditional intergovernmental treaties empower institutions within the organisation to adopt binding rules, usually by a two third majority. ${ }^{36}$ In this way, Annexes to the conventions, which have the same status as the conventions themselves, can be

\footnotetext{
33 Article 39(1), with an obligation to make every effort to achieve consensus.

34 Article 39(3). Identical rules for amendment are included in Article 23 of the Smuggling Protocol.

35 UNODC: Model Law against the Smuggling of Migrants, Vienna 2010, p. 21 and 23 on Article 15; pp. 86-87, 90, 95 on Article 8

36 Article $37 \mathrm{CC}$; Article viII(b) solas; Article III SAR.
} 
adopted or amended. ${ }^{37}$ The way in which newly adopted rules become binding for states varies. New or amended ICAO Annexes become formally binding on individual member states unless a particular state has notified the ICAO that it finds it "impracticable" to fully comply; the ICAO will notify all other member states of this. ${ }^{38}$ Under solAs, individual states are free not to accept an amendment, even though it has been adopted with the required majority. ${ }^{39}$ New or amended SAR Annexes shall be communicated to all state parties for acceptance. An amendment which has been adopted shall be deemed to have been accepted if two thirds of the state parties have accepted it, but one year after the communication, an amendment will be deemed to have been accepted, unless one third of the state parties have notified their nonacceptance. ${ }^{40}$ It is unusual that a state uses the opportunity to decline acceptance of an amendment because of substantive disagreement. Significantly, Malta has used this opportunity to reject amendments concerning disembarkation of undocumented people rescued within its extensive SAR zone. ${ }^{41}$ Below, we will address the substance of this amendment. For now, it is sufficient to note that a rare case where a state used the possibility not to accept an amendment related to irregularised travellers.

Resolution 4 adopted by the conference which adopted the SAR Convention in 1979 urges states to use the guidelines laid down in two search and rescue manuals published by the forerunner of the Iм.${ }^{42}$ Both wording and content of the resolution and of the guidelines themselves make clear that these are not seen as binding. The SAR Convention stops at this level; no binding rules are established on the basis of the SAR Annex.

37 Article 54 (l) CC; Article I solas; Article I SAR.

38 Article 38 ICAO. See on this procedure extensively J. Huang: Aviation Safety and ICAO (Kluwer Law International, Alphen aan den Rijn, 2009) pp. 54-66. Article VIII(b)(vii)(1) and (2) solas. The same amendment procedure is applied to the 1988 Protocol relating to solas, including its annex, Article VI 1988 Protocol.

$40 \quad$ Article III $(3)$ (b) SAR.

41 Gallagher and David, supra note 23, p. 461. Comp. P. Mallia: Migrant Smuggling by Sea. Combating a Current Threat to Maritime Security through the Creation of a Cooperative Framework (Martinus Nijhoff Publishers, Leiden, 2010) pp. 128-140. The deposition of the government of Malta of 22 December 2005 is registered in Status of multilateral Conventions and instruments in respect of which the International Maritime Organization or its Secretary-General perform depositary functions as at 19 April 2016, p. 413, online at http:// www.imo.org/en/About/Conventions/StatusOfConventions/Documents/Status\%2o -\%202016.pdf, visited 26 May 2016.

Published as attachment to 1405 UNTS 97 , in UNTS 1985, p. 227. 


\subsection{Transnational Law-making in ICAO and IMO}

However, both the solas Annex and the relevant Chicago Convention Annex 19 stipulate that further binding rules will be adopted on the basis of the Annexes. The solAs Annex stipulates that there is an International Safety Management Code (ISM Code), ${ }^{43}$ which is characterised as binding for companies and ships. ${ }^{44}$ Furthermore, the Imo Assembly has adopted (and periodically revised) Guidelines on the implementation of the ISM Code for governments, ${ }^{45}$ and the Maritime Safety Committee and the Maritime Environment Protection Committee jointly adopted Guidelines for companies, ${ }^{46}$ as well as guidance documents. ${ }^{47}$ These are not seen as binding.

In the Chicago Convention context, the term "standards" is used for binding rules, whereas the acceptance of recommendations by member states merely expresses a political intention. Annex 19 is a comprehensive document on safety management establishing such standards and recommended practices and procedures. ${ }^{48}$ The Annex contains attachments and appendices. States are obliged to establish a State Safety Programme (SSP). Part of an SSP has to be an obligation for private actors (such as airlines) to implement a Safety Management System (SMS). The Annex, and its attachments and appendices, contain norms with which sSPs and sMss have to comply. In light of the precise terminology in the Convention, the wording of these documents is interesting. Instead of distinguishing between standards ("states shall") and recommendations ("states should"), they consistently posit things (for example: "The State has promulgated a national safety legislative framework").49 The most extensive document on the regulation of safety of air travellers is the Safety

43 Adopted in 1993 by Resolution A.741(18); adopted and amended in accordance with Article vin solas, Regulation IX.1 SOLAS Annex.

44 Regulation IX.3 SOLAs Annex.

45 Resolution A.788(19) adopted in 1995; revised Guidelines adopted in 2001 by resolution A.913(22); revised Guidelines adopted in 2009 by Resolution A.1022(26); revised Guidelines adopted in 2013 by resolution A.1071(28). Source online at <http://www.imo.org/en/ OurWork/HumanElement/SafetyManagement/Pages/Default.aspx >, visited on 18 February 2015. The consolidated version of the new guidelines is published in the Resolutions.

46 Annex to MSC-Mepc.7/Circ.5.

47 Annex to MSC-MEPC.7/Circ.6; Annex to MSC-MEPC.7/Circ.7. <maddenmaritime.files -wordpress.com/2014/o2/ism-code.pdf>.

48 Adopted by the ICAO Council 25 February 2013, $198^{\text {th }}$ Session. This reading of the difference between standards and recommendations is in line with ICAO Assembly Resolution A1-31, the wording of which is also used in Annex 19, Foreword, Status of Annex components. More extensively Huang, supra note 38 .

Annex 19, Attachment A, a.a, emphasis added. 
Management Manual (SMM). The Manual is published by the ICAO, "[a] pproved by the Secretary General and published under his authority".50 The Manual is intended to provide states with "guidance" on the development and implementation of a state safety programme (SSP) "in compliance with" the international standards and recommended practices. ${ }^{51}$ The Safety Management Manual states that standards and recommended practices "provide the high-level requirements that States must implement to fulfil their safety management responsibilities".52 Both the word "must" (in distinction from shall and should) and "responsibilities" (in distinction to obligations) obfuscate whether these standards and recommended practices are binding or not. The effect of this is that the difference between (binding) standards and (non-binding) recommended practices and procedures disappears. The texts use terms which signal that states are presumed to comply. This compliance is assumed to occur, regardless of the binding or non-binding nature of the text. This means that international civil servants draft texts which states are presumed to comply with, regardless of the formal power of these civil servants to make such rules.

\subsection{Summary: Traditional Intergovernmental versus Transnational Law-making}

The three systems described here all are based on the notion that only states have the capacity to make law that binds them. In the UNODC context, lawmaking has not moved beyond traditional intergovernmental treaty-making. In the IMO and the ICAO context, organs created by the foundational conventions have been given law-making capacity. The Annexes these organs draft contain both binding and non-binding rules. The Annexes grant specific organs the competence to establish further binding rules. There are possibilities for states not to accept amendments. However, this possibility is used infrequently. Significantly, it has been used by Malta in order to prevent Malta from being bound by new IMO rules on the disembarkation of rescued irregularised migrants. In the IMO context, in addition to this, texts like manuals and guidelines are drafted which are not assumed to be binding. In the ICAO context however, the relevant texts obfuscate which parts are binding and which parts are not, and use terminology assuming that states will comply with the rules laid down in the Annexes and even in the Safety Management Manual. On the basis of this manual, rules are produced by international civil servants. States

\footnotetext{
$5^{\mathrm{O}} \quad$ Title page of the $3^{\text {rd }} 2013$ edition.

51 SMM 1.1.2.

52 SMM par. 3.1.2.
} 
and private actors are assumed to comply, regardless of the question whether the entities which issued these rules were competent to issue binding rules.

The legal protection of the right to life is the subject of detailed and delegated forms of transnational law-making when it concerns air travel. When it comes to sea travel, there are similarly detailed and delegated forms of transnational law-making. The rules on non-acceptance of amendments formally preserve state sovereignty, which however are infrequently used; the example we saw concerns irregularised sea travellers. In sharp contrast to this, formal state sovereignty is entirely intact when it comes to making law protecting the right to life of irregularised sea travellers. This difference may be characterised as a differentiated opinio juris. The outcomes of ICAO rule-making procedures are presented as binding regardless of the formal status of the rules. The outcome of Imo rule-making procedures tends to be accepted as binding as well, but concerning irregularised travellers the possibility not to accept amendments has been activated. In the UNODC, law-making exclusively happens through traditional intergovernmental treaties.

\section{The Substance of Rules on Traveller Safety}

We will now turn to the manner in which law seeks to protect the life of cross-border travellers in the different sub-fields. In aviation law, we see a performance-based approach intervening in the details of everyday functioning of air transport. This detailed intervention is based on a comprehensive and permanent monitoring system. In regular sea travel, there is comprehensive technical regulation on the construction, maintenance and functioning of vessels, and an accident reporting system. When it comes to irregularised sea travel, law seeks to protect life through prohibition and through search and rescue. No data is collected in order to monitor the effectiveness of this approach.

\subsection{ICAO:Performance-based Approach}

The ICAO system first of all has a system of certification and licensing. Every aircraft engaged in international navigation shall carry a certificate of airworthiness as well as the appropriate licenses for each member of the crew. ${ }^{53}$ The certificates and licences are to be issued by the state in which the aircraft is

53 Article 29(b) and (c) cc. See on crew licensing extensively R. Abeyratne, Air Navigation Law (Springer, Heidelberg 2012) p. 113 et seq. 
registered. ${ }^{54}$ Certificates issued by one state party are to be recognised by other states. 55

But the essential innovation which the ICAO has brought about in the past decades is a cyclical process of monitoring procedures used in aviation, amending procedures, monitoring the amended procedures, and so on. The Safety Management Manual formulates a performance-based approach which is not about requirements for actors (such as being licenced) but focuses on the outcome of their interactions. This implies identifying measurable and objective safety indicators, ${ }^{56}$ the definition of measurable and objective targets, ${ }^{57}$ setting alert levels, and defining acceptable and unacceptable performance levels. ${ }^{58}$ Crucial for this performance-based approach is permanent process of data collection, analysis and exchange to monitor safety performance at both an individual and aggregate level (the safety data collection and processing system $)^{59}$ - a continual monitoring approach. ${ }^{60}$ For this not only data on accidents and incidents are needed, but also operational data of airline companies (to calculate frequency of accidents and incidents). ${ }^{61}$ The manual outlines how to collect data in such a manner that the number of incidents per period per number of flight hours can be measured in relation to country, carrier, fleet type, personnel, circumstances of the flight, the procedures followed during flight and so on. The acceptable level of safety performance, which is a central yardstick in this process, "is identified and established by the State's aggregate safety indicators", 62 and safety indicators are descriptive accounts of the number of incidents. ${ }^{63}$ Thus, the central normative target is described as being factual. Similarly, a term used for norm setting in this context ("data-driven") ${ }^{64}$

54 Article 31 and $32 \mathrm{CC}$.

55 Article $33 \mathrm{CC}$.

56 Par. 4.3.5.6 sмm.

57 Par. 4.3.5.7 SMM.

58 Par. 4.3.5.1 SMM ; par. 4.3.5.8 SMM.

59 Par. 4.2.30 SMM.

6 E.g.<http://www.icao.int/safety/CMAForum/USOAP\%2oCMA\%2oSSP\%2oRollout/USOAP \%20CMA_SSP\%20Rollout_vs5.pdf $>$, visited on 5 January 2016.

61 Par. 2.11.9 SMM.

62 sмM par. $4 \cdot 3 \cdot 5 \cdot 3$

63 SMM par. 2.12

64 The term is used in SM M par. 4.2.17 for contracting state's rulemaking, selection of safety indicators, target and alert settings, and surveillance programme prioritization; in par. 4.2.24, 4.4.17, Appendix 1 to Chapter 4, 1.1(f) for state's surveillance programmes; in par. 4.2 for state's targeting of their oversight; in Appendix 1 to Chapter 4, 2(2) for the state's approach to safety regulation and industry oversight. 
suggests that the data are driving level-setting, and that standards are not primarily based on normative decisions taken by human beings. ${ }^{65}$

\subsection{SOLAS: Certification and Licencing}

The solas system essentially is a certification and licencing system. Ships engaged in international voyages ${ }^{66}$ are to be issued certificates ${ }^{67}$ upon inspections before the ship is put in service, and after that periodic inspections are mandatory. ${ }^{68}$ The certificates must be readily available on board at all times. ${ }^{69}$ Certificates issued by one state party shall be recognised by other states party. ${ }^{70}$ States party can inspect whether ships in their port have a certificate, and whether there are clear grounds for believing that the ship does not live up to the relevant standards. If the ship does not live up to the relevant standards, it cannot sail until appropriate repairs have been made. ${ }^{71}$ Casualties on ships are to be investigated by the flag state, and the findings of the investigation have to be reported to the IMO. ${ }^{72}$ These reports contain no reference to incidents involving migrants, which is understandable because the companies have to initiate the report, and in smuggling the carrier is not a company likely to submit casualty reports. ${ }^{73}$ The remainder of the Annex contains detailed technical norms for both passenger and cargo ships. Training and certification of crew is the subject of a specific convention. ${ }^{74}$

65 This technical approach, seemingly excluding human influence, is also evident in passages suggesting that risks "are manifest through the analysis of" particular data analysis, SMM par. 4.2.18, comp. par. 4.2.22

66 SOLAS Annex I.1.

67 SOLAS Annex I.12.

68 SOLAS Annex I.7 for passenger ships, I.8 for cargo ships.

69 SOLAS Annex I.16.

70 SOLAS Annex I.17.

71 SOLAS Annex I.19.

72 SOLAS Annex I.21.

73 For example Casualty Statistics and Investigation. Loss of life from 2006 to date, 16 January 2012, IMO document FSI 20/INF.17; Casualty Statistics and Investigation. A report of the Correspondence Group on Casualty Analysis, 28 November 2012, IMO document FSI 21/5.

74 International Convention on Standards of Training, Certification and Watchkeeping for Seafarers, UNTS 1361, 1362. Amended in 1997, UNTS 1968, and in 1997, UNTS 2052, and the stcw Code, published by ıмо. 


\subsection{SAR: Coordination}

The international legal obligations concerning maritime search and rescue cover both regular and irregularised travellers. These rules are conceived as a mutual obligation between seafarers - a kind of insurance system. Article 98 of the United Nations Convention on the Law of the Sea (UNCLOS) ${ }^{75}$ obliges states to require the captains of ships flying its flag to render assistance to any person at sea in danger of being lost; to proceed with all possible speed to a person in distress if informed of their need of assistance, if that can reasonably be expected; and to render assistance after a collision. Furthermore, coastal states shall promote the establishment of adequate search and rescue services. The SAR Convention aims at coordinating the search and rescue activities of different states. To that end, states shall agree on search and rescue regions, in which they are primarily responsible for providing search and rescue. ${ }^{76}$

In the context of search and rescue for irregularised travellers, disembarkation has been identified as problematic. The disembarkation of rescued persons is problematic where the rescued persons are not fellow-seafarers (who will usually be entitled to disembark and in addition are usually not seen as a risk by receiving states) but migrants who are seeking to enter European states. Identifying a place of disembarkation has sometimes proven to be difficult. ${ }^{77}$ This increases the burden and financial risk which shipping companies are confronted with when they rescue migrants, and as a consequence may decrease the likelihood that they will do so. In the Imo this issue has been identified. An amendment has been adopted providing that the state in whose SAR zone the rescue took place either has to provide a place of safety, or has to ensure that a place of safety is provided (without, in the latter case, necessarily providing a place of safety on its own territory). ${ }^{78}$ Notwithstanding this compromise, the amendment has not been accepted by Malta. ${ }^{79}$ Malta has a very large SAR zone, and acceptance of the amendment would lead to Malta

$75 \quad 1833$ UNTS 397.

76 Para. 2.1.9 SAR Annex.

77 S. Trevisanut, 'Search and Rescue Operations in the Mediterranean: Factor of Cooperation or Conflict?', 25 International Journal of Marine and Coastal Law (2010) pp. 523-542.

78 Resolution MSC.155(78), adopted 20 May 2004, entry in to force 1 July 2006. Mallia, supra note 41, 131-140.

79 Communication of the government of Malta to the IMO of 22 December 2005, in Status of international Conventions and instruments in respect of which the International Maritime Organization or its Secretary-General performs depositary or other functions as at 11 February 2016, p. 414, online at http://www.imo.org/en/About/Conventions/StatusOf Conventions/- Documents/Status\%20-\%202016.pdf last accessed February 12, 2016; Trevisanut, supra note 77; comp. Mallia, supra note 41, p. 139. 
being responsible for the disembarkation (on its own territory, or elsewhere) of many people who are now disembarked in Italy. 80

\subsection{Smuggling: Combating Crime}

Since the 1990s, protecting the lives of migrants has been one of the declared aims of the criminalisation of migrant smuggling. ${ }^{81}$ Illustrative is the EU response to the discovery of 58 bodies in a truck in Dover on 19 June 2000. In a resolution the European Parliament pointed out that "similar incidents occur daily at the Union's frontiers" and states that migrants and refugees are "victims, for the most part, of smugglers and traffickers in human beings". It called upon Commission and Council to combat criminal organisations, pointing to the need for effective controls in order to stop illegal migration. ${ }^{82}$ The preamble of the Smuggling Protocol mentions saving lives as the secondary goal of the Protocol (stipulating that the states party to the Protocol are "also concerned that the smuggling of migrants can endanger the lives or security of the migrants involved"), ${ }^{83}$ the primary concern being the "great harm to the States concerned" which "the activities of organized criminal groups" cause. In Article 2 the Protocol provides that its purpose is to prevent and combat the smuggling of migrants, while protecting the rights of smuggled migrants. This also puts the combat of smuggling first, and the protection of rights of migrants (including, presumably, their right to life) as an additional aim. The Smuggling Protocol defines migrant smuggling as the procurement for direct or indirect financial or other material benefit of illegal entry. ${ }^{84}$ The core obligation of states party to the Protocol is to criminalise migrant smuggling. ${ }^{85}$ Specific provisions on migrant smuggling by sea stipulate that states party to the Protocol shall cooperate to the fullest extent possible to prevent and suppress migrant smuggling by sea, in accordance with the international law of the

8o Mallia, supra note 41, p. 78. Malta's interest in a large SAR zone is in the fact that the SAR zone coincides with its Flight Information Region (FIR), see < gis.icao.int/flexviewer/>, visited on 5 October 2015, and it can levy air traffic control charges for flying through it. Malta rejects the idea of having a smaller SAR zone, Times of Malta 26 April 2009, online at <http://www.timesofmalta.com/articles/view/20090426/local/shrinking-maltas -search-and-rescue-area-is-not-an-option.254380>, visited on 5 October 2015.

$81 \quad$ Supra section 2.2 .

82 EP Resolution on illegal immigration and the discovery of the bodies of 58 illegal immigrants in Dover, 6 July 2000, OJ C 121/396, 24 April 2001.

83 Emphasis in original.

84 Article 3(a) Smuggling Protocol.

85 Article 6 Smuggling Protocol. 
sea. ${ }^{86}$ The Protocol develops a framework of cooperation aimed at suppressing the use of boats for smuggling, by dealing with boarding, searching and taking other appropriate measures against smuggling vessels. The major problem addressed by this cooperation is how to reconcile taking action by coastal states with the exclusive jurisdiction of the flag state. States are to request permission from the flag state, and requested states are to respond quickly. 87

\subsection{Reporting Systems}

As we have seen above in section 4.1, a continual reporting system lies at the basis of the ICAO's continual standard-setting procedure. This leads to detailed and rich data on air traveller safety. ${ }^{88}$ The IMO does not have such an extensive and permanent reporting system, but casualties on ships have to be investigated and reported. This likewise leads to detailed data which logically are about regular sea travellers (see above section 4.2). ${ }^{89}$

In 1998, the IMO initiated a reporting system on "unsafe practices associated with the trafficking and transport of migrants by sea". It created a report format for doing so, which however does not contain boxes for issues concerning safety. The only box where this might be addressed is the last one, entitled "Brief Description of Incident and Measures taken (including date/time as necessary)". ${ }^{90}$ Whereas the IMO started out with a concern about unsafe practices related to trafficking and transport of migrants, in its reporting the safety of the migrants was not an independent topic. Safety issues are at most implicit in incident descriptions, but often even these implicit references are absent and the reports exclusively concern smuggling incidents regardless of safety issues. These may well include cases of smuggling where there was no safety problem. Recommendations concern border control, not safety. ${ }^{91}$ It is unclear which incidents were to be reported, and incidents involving migrant deaths do not occur in the reports. Because of the absence of deaths in the reporting system and the lack of information on safety issues in the reported cases of smuggling, the reporting system in practice concerns irregularised migration and not safety. In 2015, the International Organization for Migration (IOM),

\footnotetext{
86 Article 7 Smuggling Protocol.

87 Article 8 Smuggling Protocol.

88 Such as the database of airfleets.net at <www.airfleets.net/crash/fatalities_year.htm>, visited on 23 December 2015; and the ICAO Annual Safety Report, <www.icao.int/safety/ Pages/Safety-Report.aspx $>$, visited on 23 December 2015.

89 Supra note 73.

90 MSc/Circ.896, 16 December 1998.

91 For example: "Night patrols should be increased to mitigate the incidents", incident reported from Greece on 5 May 1999 in the database, infra note 92.
} 
UNODC and IMO jointly set up "a database on migrant incidents and on suspected smugglers and vessels to better understand unsafe mixed migration by sea and to take measures to address it." 92 This database turns out to be based on the previous IMO reporting system; the role of IOM and UNODC is not clear. Only three countries (Greece, Italy and Turkey) have made a significant contribution to the reporting system, and they ceased doing so between 2010 and 2012.

As a result, data on deaths during irregularised sea travel have not been collected by UN institutions, and there are no data which can be used to monitor the effectiveness of the prohibition of irregularised sea travel for reducing the risk to life. This is in sharp contrast to data on deaths in air travel and regular sea travel, which are collected and used in order to develop regulation. Data on migrant deaths have been collected by NGOs and academics, and recently IOM has begun to report migrant deaths. ${ }^{93}$

\subsection{Summary}

In safety management literature, three approaches have been distinguished. The first one is the technical approach, which focuses on material improvements, concerning for example the construction and maintenance of ships and aircraft. The second approach is the person approach, focusing on unsafe acts (errors, procedural violations), which in this perspective are primarily caused by things like lack of training, forgetfulness, inattention, poor motivation, carelessness, negligence and recklessness. Countermeasures aim at individual behaviour, using means such as amending existing procedures, disciplinary measures, litigation, retraining, naming and blaming. Errors are predominantly seen as a moral issue. The third approach, the system approach, takes as its starting point that risk-creating human behaviour in violation of norms and procedures is to be expected. An error only leads to an incident if it is combined with a simultaneous failure of defence systems. Insufficient safety is seen as the result of system factors. ${ }^{94}$ Safety regulation began with the technical approach a century ago and gradually evolved so as to embrace the person and system approaches as well.

The protection of the right to life of air travellers is based on the most advanced approach, the system approach. Most salient is the routine collection and analysis of encompassing data, which is used for permanently monitoring

\footnotetext{
92 See $<$ https://gisis.imo.org/Public/MIGRANT/Incidents.aspx $>$, visited on 5 October 2015.

93 Supra note 2.

94 See for example J. Reason, 'Human error: models and management', British Medical Journal (2000) pp. 768-770.
} 
and improving safety performance. The solAs approach is characterised by a technical approach, with an emerging attention for human factors in accident causation. The main tool is licensing and certification. Data are collected through investigation of accidents and casualty reports. The SAR context is different because search and rescue is by its very nature not preventive but reparatory: search and rescue only become necessary once people at sea are in distress. The emphasis is on the universal mutual obligation to render assistance, and on practical cooperation between states. The protection of the right to life of irregularised travellers does not fit any of the approaches identified in safety management literature, as it is based on prohibition. Enforcing the prohibition of cross-border movement of irregularised travellers is the main preventive measure, and search and rescue is only reparatory. As is to be expected of an approach to safety which is outside existing approaches to safety management, there are no official data sets of accidents and casualties. The database pretending to be one turns out to be about irregularised migration instead of safety. The effects of the law protecting the right to life of irregularised travellers are not being monitored on the basis of data collection.

\section{$5 \quad$ Jurisdiction}

In keeping with what we have seen in the previous sections, there is a differentiated approach to jurisdiction. The legal protection of the right to life in aviation law applies globally, and has in fact moved beyond the state system. In the context of regular sea travel, jurisdiction is still given quite some attention, but in innovative ways. The overlap of personal and territorial jurisdiction has innovative effects, and in some contexts states are encouraged to accept obligations outside their own territorial zones, and sometimes even in territorial zones of other states. In the context of irregularised sea travel, however, jurisdiction is important and applied in a traditional manner.

\subsection{Global Aviation Law}

The Chicago Convention opens with a provision stipulating that states have complete and exclusive sovereignty over the airspace above their territory. ${ }^{95}$ However, the Convention also provides that states should ensure that every aircraft flying over or manoeuvring within its territory, as well as all aircraft with its nationality, comply with the rules and regulations which apply in that

95 Article 1 cc. 
state. ${ }^{96}$ This overlap of personal and territorial jurisdiction would be problematic if different states would have different regulations because aircraft would have to comply with the regulation of the state where it is registered, as well as with that of all states it flies over or manoeuvres in. Logically, the same provision points out that, practically speaking, this requires uniform law because aircraft have to comply with both the law of their country of nationality and of the country where they are. The Convention furthermore stipulates that over the high seas, the rules in force shall be those established by the Convention. ${ }^{97}$ The question how a limited number of states (being those party to the Convention) could be competent to decide about the applicable law on the high seas (which are outside the jurisdiction of any state) is not addressed. This also points to the global applicability of uniform norms, which makes application of those norms over the high seas less problematic.

The combination of territorial jurisdiction (over all aircraft above or on the territory, regardless of their nationality) and personal jurisdiction (over all aircraft with their nationality), as well as the applicability of the Convention over the high seas, makes clear that the Convention applies globally. This disregards the possibility of states not being party to the Convention, or the possibility that some states party might not adopt particular amendments to the ICAO legal regime. ${ }^{98}$ The rules for situations of distress and accidents show a similar overlap of jurisdictions. States "undertake to provide such measures of assistance to aircraft in distress in its territory as it may find practicable", and they undertake in principle to permit the owners or the state of nationality of the aircraft "to provide such measures of assistance as may be necessitated by the circumstances". ${ }^{99}$ If an aircraft of one state has an accident involving death or serious injury, or indicating serious technical defects, in the territory of another state, the state in which the accident occurs will institute an enquiry, permitting the state where the aircraft is registered to appoint observers and reporting the findings in the matter to that state. ${ }^{100}$ This joint exercise of jurisdiction is reflected in practice, as after the $\mathrm{MH} 17$ downing on 17 July 2014. ${ }^{101}$

\footnotetext{
96 Article $12 \mathrm{Cc}$.

97 Article 12 CC.

98 See for an article addressing state sovereignty in this context J. Huang, 'Aviation Safety, ICAO and Obligations Erga Omnes', 8 Chinese Journal of International Law (2009) pp. $63-79$.

99 Article $25 \mathrm{Cc}$.

100 Article $26 \mathrm{CC}$.

101 This was a Malaysian aircraft with a majority of Dutch passengers crashing on Ukrainian territory controlled by separatists with close ties to Russia. Based on special agreements, the Dutch authorities led the investigation, which goes beyond what Article 26 CC
} 


\subsection{SOLAS and SAR: Playing with Jurisdiction}

The Solas Convention applies to ships flying the flag of states party to the Convention. ${ }^{102}$ However, state parties shall apply the requirements of the solAs Convention and Protocol to ships present in their ports flying a flag of a non-party state if they find this necessary. ${ }^{103}$ In other places, the solAs system similarly provides that the state where a ship is in port can exercise controls, and can prevent the ship from sailing until the ship meets the solAs requirements. ${ }^{104}$ This territorial jurisdiction over ships in port - hereafter referred to as port state jurisdiction - regardless of whether their flag state is bound by SOLAS, or of states which have not accepted amendments to the solAs system, does not sit easily with the explicit provision that states are not to be bound by amendments of SOLAs which they have not consented to. ${ }^{105}$ Similar to the situation in aviation law, the traditional concept of territorial jurisdiction (over aircraft flying over the territory or a ship in port) in fact annihilates the sovereignty of states which have not accepted particular rules. In the Chicago Convention context this is very explicit, whereas in solAs it remains implicit.

The international law of the sea obliges states to require the captains of ships flying their flag to render assistance to any person at sea in danger of being lost, regardless of where their ships are, ${ }^{106}$ so this obligation of captains is applied through personal jurisdiction. Additionally, coastal states shall promote the establishment of adequate search and rescue services, inserting a territorial element in the SAR system. The SAR Convention aims at coordinating the search and rescue activities of different states. To that end, states shall

provides for. Exemplary is that the Dutch prime minister disregarded the mixed nationalities of the passengers; discussing the efforts to transport the remains of all passengers to the Netherlands, he stated "We want our people back", Tweede Kamer 2013-2014, 33 997, nr. 11, p. 3 .

102 Article II SOLAS.

103 Article I (3) of the 1988 solas Protocol.

104 Regulation I/19, XI.1/4, XI.2/9 sOLAS Annex. An example of imposing safety rules is the introduction of the Isps code, which was in fact introduced unilaterally by the us, by introducing the requirement that any ship that has been in a port where the Isps code is not implemented may not enter Us ports. See P. Metaparti, 'Rhetoric, rationality and reality on post-9/11 maritime security', 37 Maritime Policy \& Management (2010) pp. 723-736; J. Romeiro, 'Prevention of maritime terrorism: the container security initiative', 4 Chicago Journal of International Law (2003) pp. 597-605; C.E. Carey, 'Maritime Transportation Security Act of 2002 (Potential Civil Liabilities and Defenses), 28 Tulane Maritime Law Journal (2004) pp. 295-313.

105 Article III SOLAS.

106 Article 98 UnClos. 
agree on search and rescue regions, in which they are primarily responsible for providing search and rescue. ${ }^{107}$ It is explicitly stipulated that the delimitation of search and rescue regions is not related to and shall not prejudice the delimitation of any boundary between states. ${ }^{108}$ Thus, the delimitation of search and rescue regions is - formally, at least - completely uncoupled from the delimitation of national territory, and disputes over territory, territorial waters, exclusive economic zones and such. ${ }^{109}$ The obligation for ships to render assistance is not limited in any geographical sense (most notably: it applies outside the territory of their flag state), and applies regardless of the nationality or status of the person in distress or the circumstances in which that person is found. ${ }^{110}$ An issue of concern appears to be the consent of the flag state of the ship in distress to rescue activities by other states. Rescue operations undertaken in the territorial waters of other states are possible but need permission from the state. ${ }^{111}$ Neighbouring states are encouraged to work out detailed cooperation mechanisms. ${ }^{112}$

Summing up, in SOLAS and SAR different jurisdictional concepts are combined and juxtaposed so as to reach an optimal effect. In some contexts, personal and territorial jurisdiction are made to overlap, in other contexts territorial jurisdiction and state responsibility are uncoupled. Although the step that was taken in air law, which has moved beyond the state system, has not been taken, jurisdiction is used as a flexible tool which can be used in different ways to a number of ends.

\subsection{Smuggling: Traditional Approach}

The Smuggling Protocol contains the obligation to criminalise smuggling, and does not require a link with the territory of the criminalising state. ${ }^{13}$ Furthermore, it introduces an obligation for states to cooperate to the fullest extent possible to prevent and suppress the smuggling of migrants by sea. ${ }^{114}$ This implies that states party to the Protocol claim universal prescriptive jurisdiction. For enforcement jurisdiction, the picture is more complicated. The Protocol

\footnotetext{
107 Para. 2.1.9 SAR Annex.

108 Para. 2.1.7 SAR Annex.

109 But see Trevisanut, supra note 77 on Greece and Turkey.

110 Para. 2.1.10 SAR Annex.

111 Para. 3.1 SAR Annex.

112 Guidelines on the Treatment of Persons Rescued at Sea, Resolution Msc.167(78) of 20 May 2004, par. 6.5.

113 Article 6(1)(a) Smuggling Protocol.

114 Article 7 Smuggling Protocol.
} 
provides that states have enforcement jurisdiction vis-à-vis vessels in their territorial waters (provided there are reasonable grounds to suspect that the vessel is smuggling migrants, which means it cannot invoke the right of innocent passage) as well as vis-à-vis vessels flying their flag. For enforcement on the high seas against ships flying another flag, flag state consent is required. ${ }^{115}$ The requested state has to "respond expeditiously". ${ }^{116}$ Together with the obligation to cooperate this means that the requested state is not free to refuse permission at will. In this manner, the system set up by the Smuggling Protocol is in line with traditional international law (flag state permission required) while at the same time slightly limiting flag state sovereignty (duty of cooperation). Enforcement jurisdiction over a flagless vessel on the high seas could be based on the effects of smuggling on the territory of the state party. ${ }^{117}$

\subsection{Summary}

In the ICAO context, we see a combination of overlapping territorial and personal jurisdiction which presumes a unified global legal regime where issues of jurisdiction are not a major concern. In the solAs system, port state jurisdiction allows the states who are members of the IMo to impose laws on non-member states, or on member states who have not accepted amendments to existing IMO rules. In the SAR context, we see universal applicability of the norms for mutual rescue, while at the same time territorial integrity is paramount (as in the need for flag state consent). In the smuggling context, we see traditional international law on extraterritoriality. There is a remarkable differentiation in flexibility and inventiveness, with aviation law as a playground for legal creativity, and on the other end of the spectrum the law protecting the life of irregularised travellers with a static notion of jurisdiction. The right to life of air travellers is protected though global law; that of regular sea travellers through traditional notions of jurisdiction, innovatively used; and that of irregularised sea travellers through traditional jurisdiction.

\footnotetext{
115 Article 8(2) Smuggling Protocol.

116 Article 8(4) Smuggling Protocol.

117 The basis for this could be Article 15(2)(i) Convention against Transnational Organized Crime, assuming that smuggling constitutes organised crime in the sense of the Convention, and assuming that enabling a migrant to enter and remain in the state party without permission to do so is a serious crime in the sense of this provision. Alternatively, this could be based on Article 110 UnCLOS juncto Article 7 Smuggling Protocol. See more extensively Gallagher and David, supra note 23, pp. 210-222.
} 
If we tie all these different strings together, it becomes evident that for a rather similar substantive issue - the safety of cross-border travellers states have developed three different subsets of international law protecting the right to life. The difference is directly related to the expansive notion of the right to life used for regular travellers, in contrast to the limited notion of the right to life used for irregularised travellers.

In the context of the ICAO, safety is one of the main aims of the organisation and of the regulation of air transport. There are other aims, which are acknowledged as being partly competing, and regulation seeks to strike a balance. ICAO organs have legislative powers. Because of the global nature of ICAO regulations, the possibilities which states formally have not to be bound by them are insignificant when compared to the IMO and UNODC context. In the regulations produced by ICAO bodies, the difference in Chicago Convention context between (binding) standards and (non-binding) recommendations evaporates. And what is more, ICAO issues additional documents which assume the rules therein will be followed, while it has not been granted any legislative power whatsoever. Furthermore, via the permanent reporting and monitoring system, rules are created in a way which suggests that the reporting and analysis system itself leads to the adaptation of rules. States and private actors have accepted extensive obligations in order to protect the lives of travellers. Territoriality and state sovereignty are not so much compromised as disregarded.

In the IMO context, things have not gone so far. Like in aviation law, safety is an explicit aim of the organisation and of international maritime law, and is acknowledged to compete with other aims. But there is more attention for the formal aspects of law-making; issues of territoriality and flag state consent are considered important and are being dealt with. But this happens in different manners. Port state jurisdiction reaches a situation similar to that of the ICAO, because a vessel with the nationality of a state not bound by (a particular version of) IMO made law can be subjected to the version of IMO made law to which the port state adheres. On the other hand, for search and rescue flag state consent is required. The IMO safety reporting system is rudimentary compared to that of ICAO. States and private actors have accepted significant obligations in order to protect the right to life of travellers, but they ensure that territoriality and state sovereignty are not fundamentally compromised.

In the context of irregularised migration, safety is not mentioned as an aim of the UNODC, and it is only considered a secondary aim of the Smuggling Protocol. The possible tension between this aim and the primary purpose 
(combating smuggling) is not acknowledged. The procedure for making or amending law is traditional inter-governmental law-making. It is significant that the example of Malta using the possibility to reject an amendment to IMO law occurred in the context of irregularised migration. Territoriality is a crucial component of international law concerning irregularised migration. States do not have a reporting system concerning deaths of irregularised travellers, and calls to create one ${ }^{118}$ went without any formal response. States act as if they have no responsibility to prevent risks to life of irregularised travellers because they die outside their territory and rely on non-state actors such as smugglers. The responsibility of states to prevent these deaths stops with their effort to exclude these travellers from their territory. ${ }^{119}$ Because these travellers do not comply, states feel they do not have to protect the right to life of the people concerned beyond search and rescue - an obligation which is only triggered when the risk to life already has materialised.

Partly, the differentiation between the ways in which states deal with the obligation to respect the right to life may be related to the extent of control over human movement. State control over air traffic is enormous because aircraft of any significance need airports. Because of the investments in technical equipment, airports tend to be big in size and relatively few in number. Therefore, states are able to control air travel quite tightly. For sea travel, this is true to some extent as well. Larger vessels need harbours of considerable size, and states are able to control these - to a lesser extent than airports, but still it is hard for a larger boat to enter a harbour without being noticed by the authorities. Irregularised travellers seek to evade state controls. Sometimes migrants seek to escape only exit controls, and actively try to be picked up by the receiving states. But it is in the very nature of irregularised migration that states are not well able to control it.

While it is true that the level of obligations states take with respect to the right to life of travellers may be related to the level of control they have over a particular form of travel, that is not the end of the story. In the context of irregularised migration, states rely on territorial jurisdiction and the role of private

118 T. Spijkerboer, Policy Conclusions, 12 May 2015, <http://www.borderdeaths.org/wp -content/uploads/Policy-Conclusions.pdf >, visited on 23 December 2015.

119 More extensively T. Spijkerboer, 'The Human Costs of Border Control', 9 European Journal of Migration and Law (2007) pp. 147-161; T. Spijkerboer,'Are European States Accountable for Border Deaths?', in S. Juss (ed), Research Companion to Migration Law and Theory (Ashgate, Aldershot 2013), pp. 61-76; T. Spijkerboer, 'Moving Migrants, States and Rights. Human Rights and Border Deaths', 7 Law and Ethics of Human Rights (2013), pp. 213-242. 
actors to deny their obligations under the right to life. ${ }^{120}$ However, in aviation law territoriality does not play a role of any significance, and the fact that airlines are private companies is not used to deny state responsibility for legal protection of the right to life. Apparently, the legal hurdles used for denying state responsibility for traveller deaths can be taken - if states choose to do so.

So what we see is a differentiated approach to the right to life. Regular travellers benefit from extensive positive obligations to safeguard their right to life, and are protected against the possible primacy of other legitimate aims of regulation (such as expansion of travel and fair competition). Irregularised travellers are denied the benefit of positive obligations under the right to life. States deny that other legitimate aims may compete with the right to life, and deny they have any responsibility. Just to be sure, they do not put in place reporting systems to monitor the safety of irregularised travellers. Because of this lack of data, the possible tension between the right to life and combatting irregularised migration cannot come to light.

\section{$7 \quad$ Wasted Lives}

Giorgio Agamben has analysed migrants as being legitimate targets of state repression, exempted from the protection of law. However, people who try to cross borders into Europe, North America and Australia in an irregularised manner are not such homini sacri in the sense of Agamben's work. ${ }^{121}$ Irregularised travellers die not because they are targeted by states of destination, but because they are ignored. They are more fruitfully associated with Zygmunt Bauman's notion of wasted lives. In Bauman's analysis, migrants and refugees are people who cannot be included in the modern economy as workers or consumers. Whereas previously such superfluous people would move from colonising countries to new population colonies, modernisation has now become global and the 'surplus population' has become irregularised migrants and refugees 'wandering the routes once trodden by the 'surplus population' ... only in a reverse direction". ${ }^{22}$ While homini sacri are the legitimate targets of order-building, the 'surplus population' is systematically ignored by states, because it consists of people whose position is a by-product of impersonal global processes.

\footnotetext{
120 Comp. Spijkerboer 2007, 2013, ibid.

121 G. Agamben: Homo Sacer. Sovereign Power and Bare Life (Stanford University Press, Stanford 1998).

122 Z. Bauman, Wasted Lives. Modernity and Its Outcasts (Polity Press, Cambridge 2004) p. 73.
} 
No one gives the commands, no one bears the responsibility, as the baffled and desperate hero of John Steinbeck's Grapes of Wrath learned much to his dismay: wishing to fight, gun in hand, in defence of his no longer 'economically viable' farm, he could not find a single malevolent perpetrator of his torment and distress to shoot. ${ }^{123}$

The predicament of irregularised travellers is the outcome of a complex social process, involving many actors (including the travellers themselves) in different geographical locations. The effects on the individuals themselves are clear, but it is hard to relate individual deaths to individual acts by individual actors. The travellers are affected by multiple overlapping jurisdictions - that of their country of origin and of the country where they find themselves via personal and territorial jurisdiction. But they are also affected by the prescriptive jurisdiction of potential countries of destination, which enforce visa obligations extraterritorially and via private actors.

A conventional human rights analysis of border deaths is like John Steinbeck's hero trying to identify the perpetrator. ${ }^{124} \mathrm{~A}$ first problem such an analysis runs into is that border deaths often occur outside the jurisdiction of the states of destination - i.e. outside their territory and not under their effective control. Secondly, usually no representatives of any state control the situation in which irregularised travellers die, and the private actors most directly involved (the smugglers) states try to combat through criminal justice. Thirdly, it is unclear which of the potential destination states could be held responsible especially in Europe a collective of states is involved. The aim of this article was to argue that, although these doctrinal issues in conventional human rights analysis are real and genuine, they are not objective obstacles but the outcome of choices made by lawyers such as ourselves. The safety of other categories of travellers is dependent on social processes which are at least as complex as those affecting irregularised travellers. In these contexts, hard questions about jurisdiction and collective responsibility of public and private actors have been dealt with in innovative and imaginative ways. Whether the management approach to the protection of the right to life from the ICAO, or the standard setting approach from the IMO, can be a source of inspiration for increasing the safety of irregularised travellers can be the object of another paper. But it is clear that the doctrinal obstacles to human rights accountability of states are man-made choices. If human rights lawyers choose not to be as innovative and imaginative as their counterparts in aviation and maritime law, that represents

123 Ibid., 40.

124 As in Spijkerboer 2007, 2013, supra note 119. 
a choice to construct the right to life in such a manner that irregularised travellers are kept outside its scope. Irregularised travellers have become irregular because states of destination want to exclude them from their territories. For those who accept that states, as a matter of well-established international law, have the right to control migration, ${ }^{125}$ this right to exclude aliens from the territory of a state is given. However, this does not necessarily entail that these states can exclude the same people from the right to life as well.

Bauman argues that migrants and refugees are outside law as such. ${ }^{126} \mathrm{He}$ suggests that they are outside the law as a matter of structural or logical necessity. This is an overstatement. In a traditional human rights analysis, positive obligations of destination states to protect the life of people whose movement they had made irregular, are very limited. However, this is not a matter of structural or conceptual necessity but a consequence of human acts, which can be changed.

125 As per EctHR 28 May 1985, Abdulaziz, Balkandali and Cabales v United Kingdom, 9214/80, 9473/81, 9474/81; but see M.B. Dembour, When Humans Become Migrants. Study of the European Court of Human Rights with an Inter-American Counterpoint (Oxford University Press, Oxford, 2014) pp. 117-119; B. Schotel, On the Right of Exclusion. Law, Ethics and Immigration Policy (Routledge, Abingdon, 2012) pp. 27-36.

126 Bauman, supra note 122, p. 76. 